\title{
EL DERECHO PROCESAL Y LA PROTECCION DEL CONSUMIDOR *
}

\author{
ADOLFO GELSI BIDART * * \\ SUMĀRIO: I) Sentido del tema. - II) Aspectos tra- \\ dicionales a conservar o subrayar. - III) Perspectivas \\ de innovación. - IV) Conclusịones. - \\ I) SENTIDO DEL TEMA.
}

1. Significación y reconocimiento del proceso.

Cada vez que um problema adquiere por su novedad o su extensión desusada, especial significación en la sociedad, se plantea el problema de si el proceso, tal como está reglamentado, es suficiente para su protección.

Esto significa un reconocimiento de la trascendencia del proceso que, en el plano de las situaciones concretas de la vida social, siempre llega a ser; en el extremo, el único medio jurídico eficaz.

Paralela, aunque diferentemente, a lo que ocurría en el Derecho Romano clásico, en el cual el Pretor acordaba la acción cuando entendía que una situación merecía la protección judicial: "existió antes la protecctión y de ella derivó el derecho sustantivo" (1). Ahora, es apotegma del Derecho Procesal, que éste se encuentra al servicio de todo el Derecho Sustantivo, para solucionar todo problema concreto que por otra vía no quepa resolver.

En el planteamiento aludido, pues, apunta una duda central, apoyada en dos comprobaciones de experiência, por cuanto el processo: a) es un instrumento milenario; podrá adaptarse al tiempo de hoy?; b) es un medio que no sólo llega, sino que ha de llegar, después que el tema ha cobrado suficiente repercusión

(•) Intervención - informe en las VIas. Jornadas Ibero - Americanas de Derecho Procesal. (Valencia - Venezuela - 6-12/VIII/1978).

(•) Professor catedrático de Direito Processual da Faculdade de Direito e Ciências Sociais da Lniversidade do Uruguai - Montevideo. 
social como para ser considerado como un problema efectivo a solucionar: podrá actuar con la celeridad que los cambios reclaman?

2. Problemas del consumidor.

Desde que nuestra época ha merecido el calificativo de 'civilización o sociedad de consumo' (al menos en algunos países y para algunos sectores, más o menos extendidos) se ha planteado, como contrapartida la necesidad de proteger al consumidor, según preocupaciones que al respecto establecen los diversos órdenes jurídicos, para asegurar la calidad de los productos; su precio; eventualmente, los contenidos publicitarios que los promueven.

Se procura salvaguardar (?) la libertad y la lealtad en las relaciones económicas, a través de diferentes soluciones que reglamentan la propaganda, fiscalizan los precios (cuando se han fijado oficialmente) o la calidad de los productos. Generalmente hay oficinas especiales (municipales, provinciales, nacionales) que tienen a su cargo tales actividades.

3. Lo sustantivo y lo procesal.

Es suficiente la reglamentación sustantiva o también se impone la procesal?

Está claro que esta última habrá de realizarse según su propio 'modus operandi', vale decir, cuando corresponde efectuar el proceso. Pero se imponen dos preguntas:

a) Se requerirá alguna peculiaridad en el proceso o éste habrá de operar en su forma tradicional, aunque, tal vez, poniendo el acento en algún aspecto en particular?

b) Será conveniente programar alguna innovación en el processo en cuanto a los sujetos o en su estructura, para dar mayor efectividad al proceso, en defensa del consumidor, en especial teniendo en cuenta la relativa generalidad de éste?

\section{II) ASPECTOS TRADICIONALES DEL PROCESO, A CONSERVAR O SUBRAYAR.}

4. Garantía según el 'modus operandi' procesal.

Sustentamos la firme convicción de que no corresponde buscar un proceso para cada situación, por cuanto, se volvería, por vía indirecta, a la concepción clásica romana (ut supra) o a la 
concepción de la época 'moderna' (no de la actual) del procesoapendicular del D. Sustantivo.

Se trata, por el contrario, de proporcionar este instrumento que, con leves variantes, puede ser aplicado a las diferentes materias: la diversa naturaleza de éstas no requiere la modificación de aquél, en sus aspectos esenciales.

5. 'Debido proceso en legal forma'.

Por ende, la ocasión del proceso, la que da lugar al mismo, - necesidad de determinar (y aplicar) el derecho al (o del) caso concreto - y la estructura fundamental del processo, - 'debido proceso en legal forma' - habrán de ser respetadas.

De ahí que entendamos que un proceso como el que se consagra para la aplicación y ejecución de multas establecidas por el Consejo Nal. de Subsistencias y Contralor de Precios, organismo encargado de esta tarea y que no brinda el mínimo de garantías procesales de defensa (ser oído y probar sus asertos), debe ser rechazado, por su intrínseca inconstitucionalidad. 'La eficacia represiva debe realizarse según la modalida - 'garantizadora' del proceso en sí (2).

\section{Inspección judicial y pericia.}

Las peculiaridades de los problemas del consumo, llevan a subrayar la importancia que tienen al efecto, determinados medios de prueba, en especial la inspección judicial y la pericia; esta última debe considerarse como 'prácticamente' necesaria y se puede pensar en que la ley pueda calificarla así, para imponeria en todo proceso en que deba actuarse acerca del tema.

\section{El 'derecho de respuesta' y el proceso.}

En el plano de la propaganda, son las leyes denominadas 'de imprenta' y que hoy deberían interpretarse con amplitud, 'de medios de comunicación masivos', - las que pueden brindar un camino para evitar no sólo los excesos de las mismas en otros planos (ataque personal, separación del mínimo padrón acerca de las 'buenas costumbres'), sino también en el ataque a la libertad del consumidor (v. gr. propaganda 'sub-liminar') o en los casos de des-ajuste entre el contenido de la propaganda y la realidad del producto.

Se ubica aquí, además de las sanciones en el plano adminis- 
trativo y en el penal, - el 'derecho de respuesta' o 'de rectificación', - que también podrá ser empleado en defensa del consumidor y que habría de seguir el trámite procesal pertinente, en caso de ser resistido (3).

\section{III) PERSPECTIVAS DE INNOVACIŌN.}

8. Interés a promover.

a) Nuestro ordenamiento jurídico dispone que para ser parte en el proceso, se requiere tener un interés directo en el mismo, o sea, que afecte la esfera jurídica de la que es titular. Esto se expresa al reglamentar el instituto de tercería y en el proceso administrativo de nulidad.

"Tercero opositor es aquél cuya pretensión se opone a la del actor, coadyuvando a la del reo, o viceversa y a veces a la dos: en el 1 ? caso se llama coadyuvante y en el $2^{\circ}$. excluyente" (C.P.C. art. 520). "Tanto los terceros opositores excluyentes como coadyuvantes, deben fundar sus derechos en un interés propio: este derecho debe ser positivo y cierto en su existencia, aunque su ejercicio dependa de algún plazo o de alguna condición que debe llegar" (art. 521).

“La acción de nulidad sólo podrá ejercitarse por el titular de un derecho o de un interés directo, personal y legítimo, violado o lesionado por el acto administrativo" (Constitución art. 309 inc. 3).

b) En el caso, pues, en que el consumidor que inicia el proceso es un sujeto de derecho cuyo interés ha sido efectiva y concretamente lesionado por el industrial o el comerciante respectivo, - nos encontramos en las situaciones corrientes, que conducen y se ventilan en el proceso.

c) Pero el modo que más peculiarmente incide en el tema de la protección al consumidor, es cuando no existe (procesalmente hablando) una persona que ha sido lesionada en su interés.

Generalmente es así, porque el 'quantum' del daño es mínimo y, en todo caso, no motiva suficientemente a cada consumidor, como para promover um proceso al respecto. Desde otro punto de vista, las consecuencias (indemnizar al damnificado) por su relativa insignificancia y los escasos procesos que se promueven, - no son suficientes como para hablar de una efectiva garantía procesal al consumidor.

d) Nos encontramos, pues, en el campo de lo que se llama por algunos 'intereses difusos', no porque no haya personas que 
puedan considerarse sus titulares, sino por lo que acaba de indicarse (supra c), con lo cual no aparecen, de hecho, quienes los reclaman. $Y$, aunque aparezcan, siempre hay muchos más afectados, que, de hecho, no tienen protección procesal, pues no la requieren (4).

e) Será lógico, entonces, preocuparse por quienes pudiendo hacerlo no actúan, según las reglas tradicionales? O habrá que procurar soluciones nuevas, por cuanto el interés en cuestión excedería, iría más allá, de la situación concreta de cada uno de los afectados efectiva o posiblemente?

9. Interés del consumidor e interés general.

a) Es clara la existencia de interés de los consumidores en no ser engañados y en no pagar precios excesivos; este interés puede considerarse abstractamente igual en cada consumidor, por ende: en todos. Se encuentra extendido, difundido (de ahí: interés difuso) entre todos los que se encuentran en tal condición, es decir, en todos los habitantes del país (cada uno es, potencialmente, consumidor de ....).

Por tanto, el interés del consumidor (de- los consumidores) es, en rigor estricto, un interés general, no individual o particular, sin perjuicio de que se concrete en uno u otro de los mismos. Cuando esta concreción se realiza (este consumidor adquiere un objeto que realmente tiene calidad diferente a la pregonada), puede decirse que es un ejemplo, un síntoma, de esa situación general en que todos los consumidores se encuentran.

La propaganda y el comercio, se dirigen a todos, 'quives et de populi'; lo que ocurre a uno, puede ocurrirle a cualquiera. Cada uno es considerado como cualquiera, es decir, como 'todos' individualizado ejemplarmente.

b) A lo cual se añade la importancia que el legislador asigna a ese interés: un interés jurídicamente significativo $y$, por ende, garantizado en su satisfacción por el ordenamiento jurídico.

c) Este punto de vista sustantivo tiene, obviamente, trascendencia procesal, por cuanto el interés a promover, eventualmente a asegurar o a satisfacer. - es el que se da fuera del proceso y que llega a éste, como al instrumento apto para lograr su consagración.

Naturalmente que la satisfacción que eventualmente se logra, se obtiene 'según el modo procesal', es decir, en relación con un caso concreto y para aplicar las normas correspondientes al mismo, sin perjuicio de la trascendencia que pueda lograrse para 
otras situaciones, del resultado a que se llegue en el proceso ('difusión' o 'irradiación' del resultado, v. gr. porque se aplicó una multa, o se condenó a los daños y perjuicios ocasionados en el caso 'sub-examen').

d) Esto indica que el perjuicio ocasionado a un consumidor puede encararse, como de costumbre, como productor de insatisfacción en el interés individual del mismo.

Pero también (además), se puede tomar en cuenta que la apelación al público del comerciante, convierte a ese 'quidam' que compró la mercadería, en representativo de una situación de gran amplitud e idéntica para todos los consumidores reales o posibles de ese objeto.

e) Por ende, sí, el consumidor dañado puede promover el proceso para satisfacer su interés individual y nadie más que él puede hacerlo. Pero quién promoverá el interés de la clase o conjunto de los consumidores?

\section{Legitimación para actuar.}

El problema se resuelve en una cuestión de legitimación: quién puede promover la garantía procesal de dicho interés general (o genérico)?

Según la mayor o menor proximidad del legitimado para actuar con el interés afectado, la coincidencia más o menos alejada con el mismo, caben varias soluciones y probablemente la solución más adecuada sería admitirlas todas concurrentemente.

a) 'Actio popularis': cualquiera del pueblo puede promover la acción, en cuanto consumidor, y por ende, en cuanto es titular del interés directo, concreto, y personal y, además, en cuanto integra el conjunto $\mathrm{y}$, por tanto, puede considerársele representativo de los consumidores.

El aspecto favorable de esta solución radica en que el impulso para el ejercicio de la acción lo da siempre el interés y cuando éste es, al mismo tiempo, genérico (todos los consumidores) e individual (este consumidor), parece asegurarse mejor la participación del litigante en el proceso.

b) Reconover la personería de las asociaciones representativas de los consumidores o de algún sector de los mismos o, en general, de las asociaciones de interés social o sinfines de lucro.

Estas asociaciones que están al servicio de sus integrantes en la prosecución de un interés con alcance relativamente amplio (y no particularizado), reúnen la doble condición de preo- 
cuparse por los problemas de sus asociados como finalidad propia de las mismas (y por ende, con el fin de cumplir su objetivo estarán en adecuadas condiciones para actuar en el proceso); por otra parte, el no tratarse del interés de la asociación misma, le otorga un mínimo distanciamiento para dar más racionalidad a lo planteado.

c) Encomendar el ejercicio de las acciones al Ministerio Público, en cuanto le incumbe "representar y defender la causa pública" (C. Org. Trib. art. 171 - inc. 10.), en la medida en que se estime que realmente la misma está comprometida ante el abuso cometido contra los consumidores.

Aquí se acentúa el distanciamiento y, por ende, la relativa 'im-parcialidad' del órgano público frente al interés comprometido y que, sin embargo, debe promover, de semejante manera a lo que ocurre en el proceso penal.

Claro está que ello puede ir unido a los peligros del 'burocratismo' y a la menor preocupacion consiguiente por la defensa de los problemas cotidianos del consumidor (5).

\section{IV) CONCLUSIONES.}

11. 1) El 'modus operandi' procesal.

La protección procesal del ccnsumidor no debería diferir en su 'manera' de otorgarse, de la que es propia del proceso, cualquiera sea la materia a la que se aplique.

2) Garantías.

a) Las garant ías a reconocer a las partes deben ser las que se otorgan, por igual, a ambas, en el régimen vigente, - evitando que la intención de proteger al consumidor, desequilibre al proceso en perjuicio de uno de los litigantes: desde que se ingresa al proceso, el principio de igualdad de las personas ante la ley se transforma en el de igualdad de las partes en el proceso.

b) Debería hacerse un uso adecuado y flexible del instituto de las medidas cautelares, para suspender de inmediado las consecuencias nocivas y precaver la efectividad de la sentencia.

3) Significación de la inspección judicial y de la pericia.

Por la índole de las cuestiones, la pericia aparecerá como necesaria de hecho y aún debería establecerse, de derecho. 
La aproximación del juez a la realidad por la prueba, convendrá que se realice con la utilización del medio judicial por antonomasia, la inspección, cuando corresponda.

4) Legitimación procesal y eficacia de la sentencia.

El problema tal vez más importante, radica en la determinación de la legitimación para actuar en el proceso y, por ende de la eficacia de la sentencia, en virtud de la regla de congruencia entre la pretensión y el fallo (y sus respectivos alcances).

Además de el o los organismos que actúan administrativamente en defensa del consumidor y que acuden al proceso para la aplicación y ejecución de sanciones (a), podría ser conveniente el reconocimiento de una pluralidad de soluciones concurrentes (b); algunas ya legalmente establecidas, Ministerio Público, en cuanto se haga ingresar en el interés general o social el del consumidor (b'), otras a consagrar expresamente, como la 'actio popularis' $\left(b^{\prime \prime}\right)$, o la legitimación para actuar de las asociaciones de interés social o sin fines de lucro (b"').

1. Blas E. Rossi Masella "Manual de Derecho Romano - Procedimiento Privado Romano", p. 36.

2. v. Gelsi "Procéso y garantía de derechos humanos" - "Revista de Derecho Procesal Ibero - americana", nro. 1 - eneromarzo 1971, nota (35), p. 51-53, sobre Ley 23.X.1941 - art. 12 inc. 5.

3. v. Gelsi "Garantías procesales y conflictos socio-políticos", cap. I).

4. v. Enrique Vescovi: "Tareas del Ministerio Público en el proceso civil"; numerales 7-11 en "Towards a justice with a human face", Kluwen - Atnwerpen/Devenport. 1978, p. 471-82; Mauro Cappelletti - J. A. Jolowicz; "Public interest parties and the active role of the judge in civil litigation", Milán, Giuffré - New York - Oceanía 1975, cit. por el anterior; - E. Vescovi: "El M. P. y la tutela de los intereses difusos en el proceso civil". Revista Uruguaya de Derecho Procesal, 1976 , no. 2, p. 69-88.

5. v. Gelsi: "La humanización del proceso" en "Towards a justice with a human face", p. 271-73. 